\title{
ACM's FY13 Annual Report
}

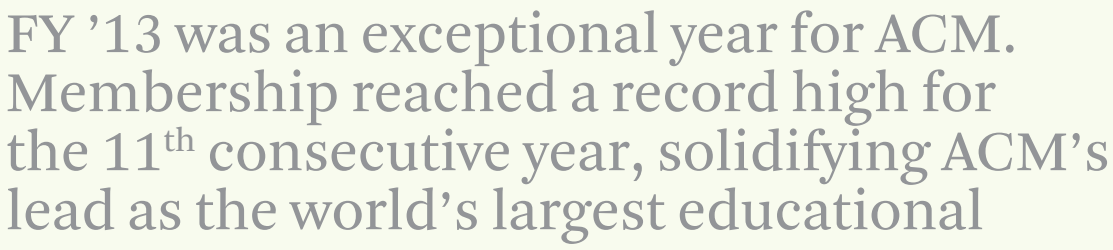

and scientific society in computing. Recognizing the expressed desires of our membership and the research community at large, ACM took a bold new approach to-and stand onopen access publishing, one that will no doubt set the tone for other professional organizations. We witnessed the steadfast commitment and global impact of our hubs in Europe, India, and China. And we continue to enrich ACM's pledge to educate future generations about the wonders of computer science with new initiatives and joint efforts that share our resources with the world.

Last April, ACM ushered in several publishing policy changes that increased access to its journals and conference proceedings. The changes were designed to balance the needs of authors and researchers in the computing community by expanding author rights as well as enabling SIGs to sponsor the open access to their most current proceedings. These latest policy changes serve as another step forward in an ongoing process in which ACM adapts to the new realities of scholarly publishing and prepares for an open access future.

ACM's international initiatives continue to flourish with ACM Europe, ACM India, and ACM China working to build a greater following in these territories by spreading the word and sharing the resources with technology associations and educators worldwide. Indeed, ACM Europe was officially incorporated as a legal entity in Europe this June-a remark- able feat for an organization less than four years old. With this status, ACM Europe can participate in discussions with the European Union on such topics as computing research, technology policies, and education priorities.

Education is the heartbeat of ACM: be it steering the computing curriculum for students and educators; taking the lead in equipping $\mathrm{K}-12$ teachers with the tools and talent to teach next generations; providing publications of the highest quality to nourish today's professionals and scholars; or advising policymakers on the merits of computing as a core component to a student's future. I was proud to be part of the first Heidelberg Laureate Forum (HLF)-an event aimed at broadening the vision of young researchers in computer science and mathematics by connecting them with many of the preeminent scientists in the field. The inaugural HLF gathered more than 25 ACM A.M. Turing Award recipients and winners

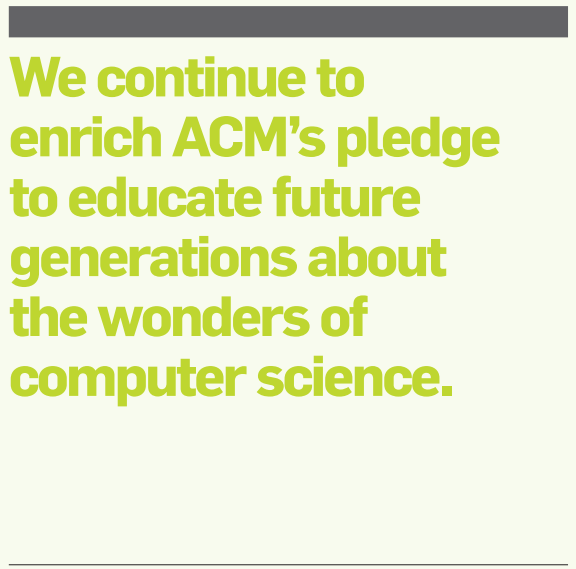

of other prestigious honors to share information and insights with 200 young researchers from around the world. Imagine the young student being able to sit down with the very role models that sparked their computing passions. It was an extraordinary event - a natural for ACM - and I look forward to next year's forum.

The following report lists just some of the many activities and accomplishments of the Association over the fiscal year. As I write this letter, we are deep into the first quarter of FY14, with many more plans and challenges to address. In many ways, ACM is at a turning point. With the open access movement changing community expectations about how publications should be financed and distributed; with our international presence thriving but SIG membership declining, we must look to restructure ACM's business models in order to build a robust interconnected set of current and future activities, programs, and products. This challenge is of paramount importance in the coming year. Indeed, senior ACM leaders and staff recently held a two-day retreat to sort through the options and explore new ways of thinking about products and services.

As always, we look to our devoted volunteers and members to share their insights and ideas with us. Together, we can prepare ACM for a future even more accomplished and amazing than its past.

Vinton G. Cerf, ACM PRESIDENT 


\section{Highlights of ACM Activities: July 1, 2012-June 30, 2013}

ACM, the Association for Computing Machinery, is an international scientific and educational organization dedicated to advancing the arts, sciences, and applications of information technology.

\section{Publications}

ACM leadership, along with the ACM Publications Board, responded to appeals to make the association's scholarly articles more openly accessible by spearheading a comprehensive review of its copyright policy. These efforts resulted in major changes to ACM's publishing rights model that were introduced last April. ACM authors exercise greater control of their published works as they are now offered three choices for managing rights: an authorpays open access option, an exclusive license agreement, along with the traditional copyright transfer. In addition, ACM took steps to allow SIGs to open up more of their conference content.

The centerpiece of ACM publications is the ACM Digital Library (DL) serving as the primary distribution mechanism for all the association's publications as well as host to scientific periodicals and a set of conference proceedings from external organizations. The DL, now available at 2,650 institutions in 64 countries, boasts an estimated 1.5 million users worldwide. The result of this widespread availability led to more than 15 million full-text downloads in FY13.

ACM is committed to increasing the scope of material available via the DL. Last year, over 30,000 full-text arholdings to 380,000 articles. ACM's Guide to Computing Literature is also integrated within the DL. More than 150,000 works were added to the bibliographic database in FY13, bringing the total Guide coverage to more than 2.2 million works.

ACM is the publisher of 79 periodicals, including 41 journals and transactions, eight magazines, and 30 newsletters as of year-end FY13. Durticles were added, bringing total DL

ing the year, ACM added 465 volumes of conference and related workshop proceedings to its portfolio. In addition, a collection of over 1,260 e-books is now assimilated into the DL, available to all ACM members. Moreover, the ACM International Conference Proceedings Series (ICPS) added 102 new volumes, a significant increase over FY12.

A proposal to reinstate the ACM Press Book Series was adopted by the ACM Publications Board, 12 years after the previous book series effort was discontinued. This new series, in partnership with Morgan \& Claypool publishers, will take advantage of the opportunities presented in the scholarly e-book market and focus primarily on academic-oriented research monographs and graduate-level textbooks with an emphasis on unique, innovative works.

The Publications Board's initiative to update the 1998 Computer Classification System was finalized in FY13. It was an exhaustive effort involving 160 domain experts and 13 subdisciplinespecific teams. The previous CCS terms are now mapped to the new version and all articles appearing in the DL reflect the new CSS concepts.

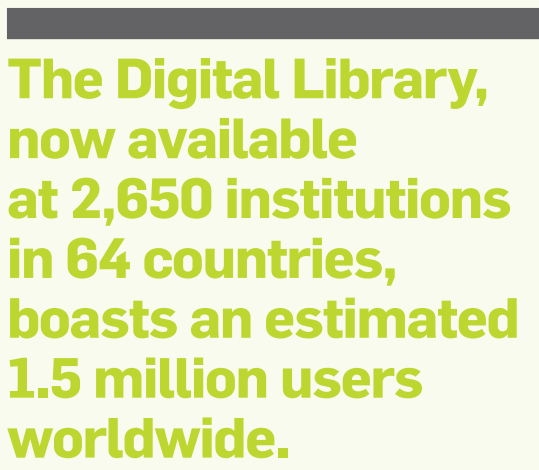

Transactions on Economics and Computation made its debut this year; next on deck is Transactions on Spatial Algorithms and Systems and Transactions on Parallel Computing coming later this year.

\section{Education}

ACM continues to lead the computer science education community through the work of the ACM Education Board, the ACM Education Council, ACM SIGCSE, Computer Science Teachers Association (CSTA), and ACM Education Policy committee.

ACM's Education Board readied results from its first survey for non-doctoral-granting institutions in computing (NDC). The goal of this annual report is to help fill the gaps in data on non-Taulbee programs and contribute a more complete view of the academic landscape in computing. Indeed, the report confirmed positive trends in enrollment and degree production at participating not-for-profit U.S. academic institutions that grant bachelor's and/or master's degrees in major computing disciplines.

A white paper addressing the growing popularity of massive open online courses (MOOCs) was published this year that outlined the challenges and opportunities presented by new technologies and current educational experiments. The work was a combined effort between the ACM Education Board, Council, and CSTA.

A 10-year effort to revise and revitalize the computer science curriculum guidelines was finalized this year with the release of the ACM/IEEE-CS Computer Science Curriculum (CS2013). Several high-level themes provided an overarching guide for the development of CS2013, including the importance of viewing CS as a discipline actively seeking to work with other disciplines; reevaluating the essential topics with enough flexibility to add new ones as needed; identifying existing exemplar courses; and understanding that curri- 
cula exists within specific institutional needs, goals, and constraints.

The CSTA continues to thrive as a key component in ACM's efforts to see real computer science exist and count at the high school level. CSTA membership increased $27 \%$ to a record 13,966 in FY13. The organization released four pivotal reports that examine the state of computer science in the K-12 environment, be it CS teacher readiness, student experiences, or major education research projects.

Under the guidance of the Education Policy Committee, ACM continued its efforts to reshape the U.S. education system to see real computer science exist and count as a core graduation credit in U.S. high schools. Working with the CSTA, the National Center for Women and Information Technology, NSF, Microsoft, and Google, ACM helped launch a new public/private partnership under the leadership of Code.org to strengthen high school level computing courses, improve teacher training, engage states in bringing computer science into their core curriculum guidelines, and encourage more explicit federal recognition of computer science as a key discipline in STEM discussions.

Several SIGs hosted innovative educational programs and special projects throughout the year. For example, one of the major objectives of the ACM SIGGRAPH Education Committee is to help establish a worldwide network of computer graphics educators. This year, the committee's initiatives were promoted at conferences in Brazil, Germany, Spain, and Mexico.

\section{Professional Development}

The Practitioners Board and Professional Development Committee (PDC) directed many new products and initiatives designed for computing professionals and managers.

The ACM PDC continued building on the success of the previous year, notably increasing the frequency and reach of its webinar program. The committee added six webinars in FY13, bringing the total number to 10. Among the featured topics: the future of the Internet; engineering SaaS; IBM Watson; and parallel computing.

The PDC also worked to tighten the integration of ACM assets such as the

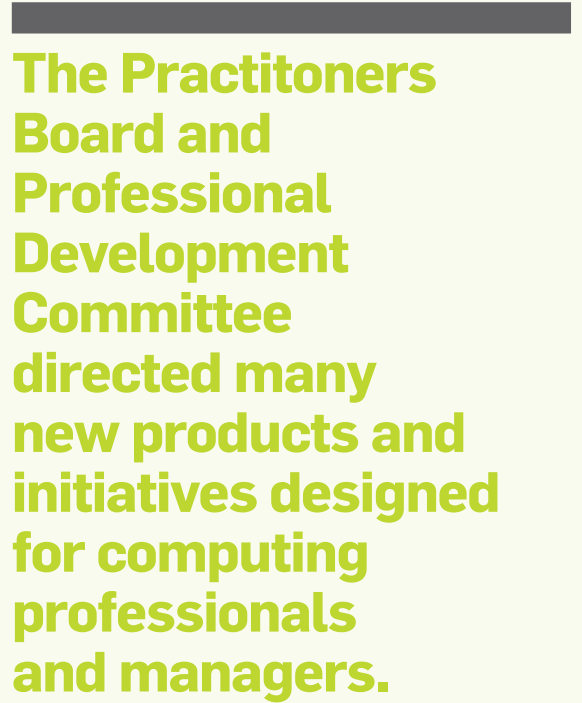

addition of Turing Centenary videos, Queue content, and other ACM learning tools like Tech Packs and podcasts in the ACM Learning Center-the hub of ACM's learning ecosystem.

$A C M$ Queue, the online practitioner's magazine spirited by the Practitioner Board, again surpassed the million-pageview threshold, with $1,039,447$ pages viewed over the last 12 months.

ACM Queue also began creating and publishing video portraits-interviews with young practitioners who are ACM members. Five portraits were published this year and the response showed great promise.

\section{Public Policy}

ACM's U.S. Public Policy Council (USACM) educates policymakers in many areas of potential legislation. This year the committee provided support, voiced opposition, or gave expert feedback to lawmakers regarding the Identity Ecosystem Steering Group, the continuity of e-government, reform of the Electronic Communications Privacy Act and the Computer Fraud and Abuse Act, and noted concerns about federal caps on scientific and technical conference spending. USACM also offered advice on how the U.S. Patent and Trademark Office and the software community could enhance the quality of software-relat-

\section{ACM Council \\ PRESIDENT \\ Vinton G. Cerf \\ VICE PRESIDENT}

Alexander L. Wolf

SECRETARY/TREASURER

Vicki L. Hanson

PAST PRESIDENT

Alain Chesnais

SIG GOVERNING BOARD CHAIR

Erik Altman

PUBLICATIONS BOARD

CO-CHAIRS

Ronald Boisvert

Jack Davidson

MEMBERS-AT-LARGE

Eric Altman

Ricardo Baeza-Yates

Cherri Pancake

Radia Perlman

Mary Lou Soffa

Eugene Spafford

Salil Vadhan

SGB COUNCIL REPRESENTATIVES

Brent Hailpern

Joseph A. Konstan

Andrew Sears

REGIONAL COUNCIL CHAIRS

ACM India

PJ Narayanan, President

ACM Europe

Fabrizio Gagliardi

ACM China

Jianguang Sun

ACM-W

Valerie Barr

USACM

Eugene Spafford

Education Board

Andrew McGettrick

Practitioners Board

Stephen R. Bourne

ACM Headquarters

EXECUTIVE DIRECTOR/CEO

John R. White

DEPUTY EXECUTIVE DIRECTOR/ COO

Patricia M. Ryan 
ed patents and outlined ways in which technology issues should be treated in the context of voting systems and election reform.

The Committee on Computers and Public Policy assists ACM in a variety of internationally relevant issues pertaining to computers and public policy. CCPP's respected ACM Forum on Risks to the Public in Computers and Related Systems, designed to discuss potential and serious computer-related risks with a global audience, covers such issues as human safety, privacy, election integrity, and societal/legal responsibilities.

The Education Policy Committee and CSTA remains deeply involved in Computing in the Core coalition efforts to increase access to rigorous computing courses for all students. In the last year, CSTA members participated in many events promoting education initiatives on this front and met with legislators to discuss STEM education issues.

The Committee on Professional Ethics (COPE) engages in a variety of projects to promote professionalism and ethical behavior consistent with and supportive of the ACM's position on professional ethics. Along with crafting workshops devoted to methods of teaching ethics and decision making, COPE endorsed the Pledge of the Computing Professional and worked with other computer societies nurturing ethics.

SIGCHI's International Public Policy Committee is finalizing a report to serve as a foundation for the topic of human-computer interaction and public policy.

\section{Students}

The $37^{\text {th }}$ Annual ACM International Collegiate Programming Contest (ACM-ICPC) took place in St. Petersburg, Russia, with 120 teams competing in the World Finals. Earlier rounds of the competition included nearly 30,000 contestants representing 2,300 universities from 91 countries. Financial and systems support for ICPC is provided by IBM. The top four teams won gold medals as well as employment or internship offers from IBM.

The ACM Student Research Competition (SRC), sponsored by Microsoft Research, continues to offer a

Balance Sheet: June 30, 2013 (in Thousands)

\section{ASSETS}

Cash and cash equivalents

$\$ 35,237$

Investments

69,608

Accounts receivable and other current assets $\quad 5,766$

Deferred conference expenses and other assets $\quad 6,045$

Fixed assets, net of accumulated depreciation and amortization

983

Total Assets

$\$ 117,639$

\section{LIABILITIES AND NET ASSETS}

Liabilities:

Accounts payable, accrued expenses, and other liabilities

$\$ 10,442$

Unearned conference, membership, and subscription revenue

24,683

Total liabilities

$\$ 35,125$

Net assets:

Unrestricted

75,800

Temporarily restricted

6,714

Total net assets

82,514

Total liabilities and net assets

$\$ 117,639$

Optional Contributions Fund - Program Expense (\$000)

Education Board accreditation

$\$ 95$

USACM Committee

Total expenses

$\$ 115$

unique forum for undergraduate and graduate students to present their original research at well-known ACMsponsored and co-sponsored conferences before a panel of judges and attendees. This year's SRC saw graduate and undergraduate winners compete against more than 219 participants in contests held at 17 ACM conferences.

The ACM-W Scholarship program further enhanced its support for women undergraduate and graduate students in CS and related programs. The committee awarded 33 student scholarships in FY13 to students to attend research conferences around the world.
SIGPLAN's mentoring initiatives are designed to encourage and support the next generation of the programming languages community. Like all ACM SIGs, SIGPLAN supplies financial support for students to attend conferences. Moreover, the group supports a Programming Languages Mentoring workshop to encourage students to pursue careers in this field.

\section{Internationalization}

ACM Europe was incorporated into a legal entity in FY13. As a legal entity, ACM Europe is now able to engage and influence EU-wide policy and par- 
Statement of Activities: Year ended June 30, 2013 (in Thousands)

\begin{tabular}{|c|c|c|c|}
\hline \multirow[b]{2}{*}{ REVENUE } & \multicolumn{3}{|c|}{ Temporarily } \\
\hline & Unrestricted & Restricted & Total \\
\hline Membership dues & $\$ 8,574$ & & $\$ 8,574$ \\
\hline Publications & 20,207 & & 20,207 \\
\hline Conferences and other meetings & 25,424 & & 25,424 \\
\hline Interests and dividends & 1,854 & & 1,854 \\
\hline Net appreciation of investments & 2,805 & & 2,805 \\
\hline Contributions and grants & 3,634 & $\$ 1,689$ & 5,323 \\
\hline Other revenue & 234 & & 234 \\
\hline Net assets released from restrictions & 1,894 & $(1,894)$ & 0 \\
\hline Total Revenue & 64,626 & (205) & 64,421 \\
\hline \multicolumn{4}{|l|}{ EXPENSES } \\
\hline \multicolumn{4}{|l|}{ Program: } \\
\hline Membership processing and services & $\$ 807$ & & $\$ 807$ \\
\hline Publications & 11,390 & & 11,390 \\
\hline Conferences and other meetings & 23,206 & & 23,206 \\
\hline Program support and other & 9,048 & & 9,048 \\
\hline Total & 44,451 & & 44,451 \\
\hline \multicolumn{4}{|l|}{ Supporting services: } \\
\hline General administration & 10,743 & & 10,743 \\
\hline Marketing & 1,538 & & 1,538 \\
\hline Total & 12,281 & & 12,281 \\
\hline Total expenses & 56,732 & & 56,732 \\
\hline Increase (decrease) in net assets & 7,894 & $(205)$ & 7,689 \\
\hline Net assets at the beginning of the year & 67,906 & 6,919 & 74,825 \\
\hline Net assets at the end of the year & $\$ 75,800$ & $\$ 6,714$ & $\$ 82,514^{\star}$ \\
\hline
\end{tabular}

* Includes SIG Fund balance of $\$ 36,793 \mathrm{~K}$

ticipate in discussions in areas such as technology, computing research, and education.

The first European Federated Research Conference took place in Paris last May, a banner event that incorporated five conferences on diverse aspects of computing. The meeting was a significant success for a first conference held during a difficult financial climate in Europe.

Last April, ACM India hosted the first-of-its-kind celebration of Women in Computing in India, providing a unique opportunity for collective learning and showcasing work in progress for many young scholars.
This landmark event was designed to help empower women in computing in India, offering workshops and seminars focused on entrepreneurship, potential career paths, and best practices for women employees working in IT firms.

A faculty summit held last February by ACM India in cooperation with Microsoft Research India was a great success. "Scaling Up Research and Innovation in Indian Institutions" focused on education challenges in India, particularly issues facing young CS researchers and the quality and impact of MOOCs. In addition, ACM India established a new Education
2012 ACM

Award Recipients

ACM A.M. TURING AWARD

Shafi Goldwasser and Silvio Micali

ACM-INFOSYS FOUNDATION AWARD IN THE COMPUTING SCIENCES

Jeffrey Dean and Sanjay Ghemawat

ACM/AAAI

ALLEN NEWELL AWARD

Yoav Shoham

Moshe Tennenholtz

THE 2013-2014 ACM-W

ATHENA LECTURER AWARD

Katherine Yelick

GRACE MURRAY HOPPER

AWARD

Martin Casado

Dina Katabi

EUGENE L. LAWLER AWARD

FOR HUMANITARIAN

CONTRIBUTIONS WITHIN

COMPUTER SCIENCE

AND INFORMATICS

Thomas Bartoschek

Johannes Schöning

ACM-IEEE CS 2013

ECKERT-MAUCHLY AWARD

James Goodman

KARL V. KARLSTROM

OUTSTANDING

EDUCATOR AWARD

Eric Roberts

OUTSTANDING CONTRIBUTION

TO ACM AWARD

Zvi Kedem

DISTINGUISHED

SERVICE AWARD

Mateo Valero

PARIS KANELLAKIS THEORY

AND PRACTICE AWARD

Andrei Broder

Moses Charikar

Piotr Indyk

SOFTWARE SYSTEM AWARD

LLVM

Chris Lattner

Vikram Adve

Evan Cheng

ACM-IEEE CS

KEN KENNEDY AWARD

Mary Lou Soffa

DOCTORAL DISSERTATION

AWARD

Shvamnath Gollakota

HONORABLE MENTION

Peter Hawkins

Gregory Valiant

ACM INDIA DOCTORAL DISSERTATION AWARD Ruta Mehta

HONORABLE MENTION

Srikanth Srinivasan 
Committee to consider how ACM can contribute to the growth of high-quality education throughout the region.

ACM China finished its third year of operation by extending its outreach efforts to bring ACM awareness to academic institutions and industries in this vast region. With each passing year the number of conferences, chapters, and memberships established in the region increases. ACM China also continues to explore partnership opportunities with the China Computer Federation (CFF), indeed for the last two years selected articles from Communications of the ACM have been translated into Chinese and published in CFF's magazine.

An important role for the Education Board is to improve understanding of the computer education landscape on a global scale. Over the last year, the board continued to collaborate with ACM Europe and Informatics in Europe by offering guidance on computing in schools throughout Europe.

International activities and conferences hosted by ACM SIGs increase every year. KDD-2012 was a huge success in Beijing, where its closing panel session on big data drew record-breaking attendance. SIGevo held a workshop at the University of Adelaide in Australia and its GECCO conference is slated for Amsterdam. And SIGAPP held its annual Symposium on Applied Computing conference in Coimbra, Portugal.

\section{Electronic Community}

ACM rolled out a new online e-Rights Transfer application system in April, giving authors new options for managing rights and permissions. The system, now used by all ACM journals, proceedings, and magazines, completely automates the rights transfer process.

The Technology and Tools Task Force developed a Web 2.0 website, Technology that Educators of Computing Hail (TECH). This effort is a reflection of its charter to promote great teaching by providing the best technology and tools resources for computing educators.

By the end of the year, ACM magazines Communications of the ACM, ACM Inroads, and interactions became accessible as easy-to-use mobile apps for

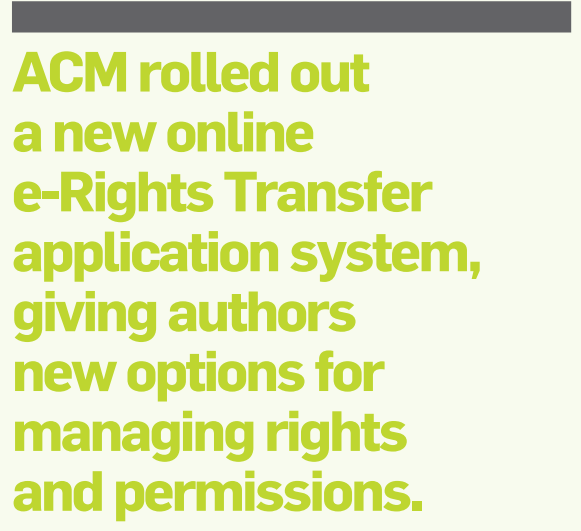

iPhones, iPads, and Android devices. These new downloadable apps enable members to access their favorite ACM magazines in a new way.

The Publications Board spirited a project to develop a webpage template to be used for all ACM journals and transactions. The result will give ACM publications a professional, uniform look and feel that enhances the imprint of one of ACM's top servicesjournal publishing.

ACM SIGs across the board continue to strengthen their online presence to build global awareness as well as incorporate social media into their operation at every opportunity. SIGACCESS, for example, enhanced its website with resources such as a set of guidelines that reflect current thinking on language for writing in the academic accessibility community as well as a guide for planning accessible conferences. The conference program for SIGUCCS 2012 was offered via a mobile app that allowed attendees to view the program, choose their sessions, and submit session evaluations using their mobile devices. SIGMOD's official blog catches the heartbeat of the community on exciting and controversial topics from posts by notable researchers and teachers in the database community. The SIG's DBJobs online service continues to attract job seekers with a database background.

\section{Conferences}

SIGGRAPH 2012 welcomed 21,212 artists, research scientists, gaming experts and developers, filmmakers, students, and academics from 83 countries to Los Angeles. More than 1,200 speakers and contributors participated in the event and SIGGRAPH's exhibition hall drew 161 industry organizations from 19 countries.

KDD-2012 attracted a record high in attendance and the number of paper submissions. In addition, the conference introduces an option for every selected paper to be accompanied by a 30-second video summary, an AsiaPacific track, and an industry practice expo that resulted in standing-roomonly attendance.

The flagship conference for the ACM Special Interest Group on Data Communication (SIGCOMM) continues to thrive in scope and attendance. This year's conference, held in Helsinki, drew over 600 attendees.

\section{Recognition}

There were 125 new chapters chartered in FY13. Of the 15 new professional chapters, all were internationally based; of the 110 new student chapters, 60 were international.

The ACM Fellows Program recognized 52 members for their contributions to computing and computer science in FY13. The new inductees brought the number of ACM Fellows to over 750 .

ACM also named 41 new Distinguished Members in FY12, of which there were six Distinguished Educators, three Distinguished Engineers, and 32 Distinguished Scientists, bringing the total number of Distinguished Members to 326.

ACM-W's Regional Celebration Committee provided support for women in computing events in Australasia, Chicago, Kentucky, New Mexico, New York, Nova Scotia, Ohio, Ontario, the Pacific Northwest, Pune (India), and the Rocky Mountain region. In addition, ACM continues to partner with the Anita Borg Institute in presenting the annual Grace Hopper Celebration of Women in Computing. 